Results The total number of examinations performed was 1022. The most common indications for EGDS were: dyspepsia 32\% ( $\mathrm{n}=327)$, abdominal pain $21 \%(\mathrm{n}=211)$, and celiac disease $16 \%(\mathrm{n}=166)$. The most common endoscopic findings were : gastritis 50\% ( $\mathrm{n}=450)$, normal findings 35\% ( $\mathrm{n}$ $=325)$ and esophagitis 9\% $(n=84)$. The most common $\mathrm{PH}$ findings were: normal 43\% $(n=390)$, gastritis $23 \%(n=210)$, and duodenitis 15\% ( $\mathrm{n}=133)$. Of the total number of examinations, endoscopy was therapeutic in $10 \%(n=98)$ of cases. The most common therapeutic indications were: foreign body ingestion 5\% ( $\mathrm{n}=51)$, PEG placement 3\% $(\mathrm{n}=35)$, and acid and alkali ingestion $1 \%(\mathrm{n}=12)$.

Conclusion The results obtainted are consistent with those of other studies and may indicate areas for additional education of staff and a starting point for future research on the topic.

\section{SCREENING FOR CELIAC DISEASE AMONG FIRST-GRADE PUPILS USING RAPID POINT-OF-CARE TEST, A PROSPECTIVE STUDY}

Kristina Baraba Dekanić*, Ivona Butorac Ahel, Lucija Ružman, Marina Milinović, Goran Palčevski. Clinical Hospital Centre Rijeka, Department of Pediatrics

\subsection{6/archdischild-2021-europaediatrics.274}

Celiac disease (CD) is an autoimmune disease triggered by gluten in genetically predisposed individuals with reported global prevalence in children from $0.31 \%$ to $0.9 \%$. Despite the increasing prevalence of $\mathrm{CD}$, many patients remain undiagnosed. Several point-of-care tests (POC) for CD have been developed that can be used as useful screening tool. We aimed to determine the prevalence of CD in first-grade pupils in Primorje-Gorski Kotar county, Croatia using POC test. Methods: Biocard celiac test that detects IgA antibodies to tissue transglutaminase in whole blood was used to screen for celiac disease in healthy first-grade children born in 2011 and 2012 who consumed gluten without restrictions. Results: 1478 children were tested and none of them were tested positive with rapid test. In 10 children $(0,6 \%)$ IgA deficiency has been suspected; only 4 of them agreed to be tested further for total IgA, anti-tTG and anti DGP antibodies. IgA deficiency was confirmed in 3 patients and in all 4 children $\mathrm{CD}$ has been excluded. Conclusion: In this, to our knowledge first prospective study in Croatia, we haven't found children with celiac disease. Further research is needed to establish the true epidemiology of $\mathrm{CD}$ in Primorje-Gorski Kotar County and to confirm the value of rapid test in comparison with standard antibody CD testing.

\section{FOOD PROTEIN INDUCED ENTEROCOLITIS SYNDROME (FPIES)}

Alemka Jaklin Kekez*, Tatjana Lesar. Helena Clinic for Pediatric Medicine, Kneza Branimira 71, Zagreb, Croatia

\subsection{6/archdischild-2021-europaediatrics. 275}

Objective The goal is to present epidemiological, clinical and laboratory characteristics of children with FPIES and the association with other allergic comorbidities and outcomes.

Methods Data of children with FPIES, diagnosed according to clinical criteria and monitored in Helena clinic over a 6-year period $(1 / 2014$ to $1 / 2020)$, was retrospectively analyzed.
Results In the specified time period, 22 children with FPIES were identified, $12(54,5 \%)$ boys, and 10 (45,5\%) girls. The median age of the first presentation was 8,45 \pm 3,96 months. An equal number of patients, 11, had early (before 9 months), and late onset FPIES. Cow's milk was the most common cause in patients with early onset, while in late it was fish. $59,1 \%$ of patients reacted to a single food, $22,7 \%$ to 2 or 3 different foods, $18,2 \%$ to 4 or more. According to clinical features, $81,8 \%$ of patients had acute manifestation, $63,6 \%$ of them mild to moderate, and $22,7 \%$ severe. $18,2 \%$ had chronic clinical presentation. 2 patients had acute and chronic symptoms induced by different foods. $36,4 \%$ of episodes were triggered by fish, $23,8 \%$ by cow`s milk, $22,7 \%$ by meat and fruits, $18,2 \%$ by cereals, $9,1 \%$ by eggs and vegetables, and $4,5 \%$ by soy. The allergic comorbidities were recognized in 16 $(72,2 \%)$ children: dermatological in $54,5 \%$, gastrointestinal in $40,9 \%$, and respiratory in 4,5\%. $17(77,3 \%)$ children underwent allergy testing. Total IgE was tested in 95,5\%, and was found positive in $6(28,6 \%)$ patients. Most of them, 5 (83,3\%), had coexisting allergy comorbidities. Atypical FPIES with positive specific IgE to trigger food was identified in 2 children. $9(37,5 \%)$ children underwent skin prick and atopy patch test to the food that was reported as the cause. Skin prick test was negative in all, while atopy patch was positive in $2(28,6 \%)$ patients. The children were followed in our clinic for a period of $17,32 \pm 10,59$ months. 7 (31,8\%) children underwent oral food challenge (OFC), at the median age $17,86 \pm 7,49$ months. 5 patients $(48 \%)$ achieved tolerance. The median period from the last episode was 12,28 $\pm 6,24$ months. We didn't find any association between the age of the patients when OFC was done, and the outcome of challenge $(r=-0,488, p=0,266)$, neither between the duration of elimination diet and the outcome $(\mathrm{r}=-, 578, \mathrm{p}=0,173)$.

Conclusion The obtained epidemiological, clinical and laboratory characteristics were similar to data from other centers. The most common identified trigger food were fish and cow's milk, which was identical to results shown in the Mediterranean countries (Italy and Spain). The outcome data also matched.

\section{ENTEROBIUS VERMICULARIS COLITIS IN CHILDREN}

${ }^{1}$ Mario Mašić* ${ }^{1,2,3}$ Iva Hojsak, ${ }^{1}$ Oleg Jadrešin, 1,2 2 anja Kolaček, 1,2ZZinjka Mišak. ${ }^{1}$ Children's Hospital Zagreb, Referral Centre for Paediatric Gastroenterology, Hepatology and Nutrition, Zagreb, Croatia; 'University of Zagreb, School of Medicine, Zagreb, Croatia; ${ }^{3}$ University of J.J. Strossmayer, School of Medicine, Osijek, Croatia

10.1136/archdischild-2021-europaediatrics. 276

Objective Infestation with pinworm (Enterobius vermicularis) is common in young children, and the most common typical symptoms are perianal itching, nocturnal restlessness, and irritability. Although the clinical presentation is usually mild or completely asymptomatic, the infestation rarely can present with non-specific colitis, weight loss, and the formation of perianal abscesses or granulomas.

Methods We retrospectively analyzed data (including medical history, age, sex, anthropometric characteristics, laboratory parameters, macroscopic and microscopic findings of ileocolonoscopy) of all patients with macroscopically proven Enterobius vermicularis. These patients were referred for diagnostic workup due to suspected inflammatory bowel disease or a bleeding polyp, from January 2010 to January 2020 at the Children's Hospital Zagreb. 